\title{
Steroid Induced Perforation of Gall Bladder-Report Of A Rare Case And Review Of Literature
}

\author{
${ }^{1, P a w a n}$ Tiwari, ${ }^{2}$ Madhu Tiwari \\ ${ }^{1,}$ Assistant Professor in General Surgery, , \\ ${ }^{2}$ Assistant Professor in Anaesthesiology, at SGT Medical college, Budhera, District Gurgaon, India.
}

\begin{abstract}
Gall bladder perforation in a serious clinical condition. A definitive diagnosis is contentious before surgery. Perforated gall bladder poses a challenge due to high morbidity \& mortality. We discuss a case of an old lady with rheumatoid arthritis, taking steroid, presented with acute abdomen. C.T. scan demonstrated a perforated gall bladder with evidence of gall stones. The patient underwent an emergency cholecystectomy and peritoneal lavage. The history and clinical findings of this patient are reviewed to high-light perforation of gall bladder in relation to steroid therapy.
\end{abstract}

\section{INTRODUCTION}

Gall bladder perforation is a rare but life threatening complication of acute cholecystitis. Sometimes gall bladder perforation may be complicated with associated co-morbidity \& treatment taken for their treatment. We report a case of 75 years old lady taking steroid for rheumatoid arthritis for last 40 years which caused the perforation of gall bladder.

\section{CASE REPORT}

A 75 years old female on methyl prednisolone for rheumatoid arthritis (Fig. 1) presented with a 5 days history of upper abdomen pain. On examination, her pulse was 100 beats/minute \& temperature was $102^{0} \mathrm{~F}$. Her white blood count was $29,100 \mathrm{~mm}^{3}$ (range 4000 to $11000 \mathrm{~mm}^{3}$ ). On abdominal examination, she had generalized tenderness \& guarding with minimal rigidity.

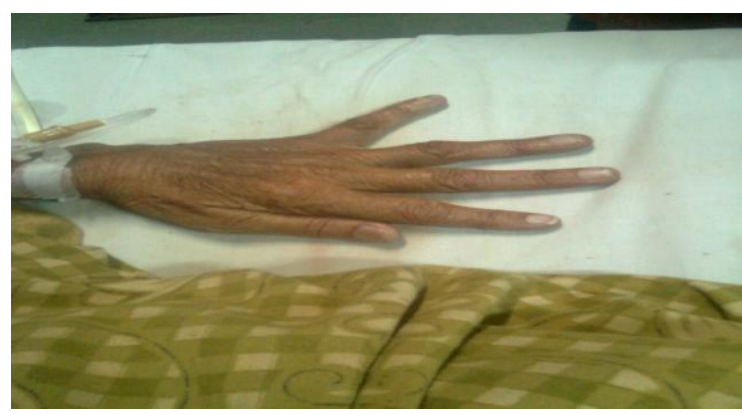

Fig. 1 shows rheumatoid arthritis in hand.

X-ray chest showed right sided pleural effusion. On USG examination showed multiple gall stones. The wall of gall bladder was thickened and showed pericholecystic collection. A C.T. scan of the abdomen showed a small rent in the body of gall bladder, consistent with a perforation along with pericholecystic and free intraperitoneal fluid (Fig. 2)

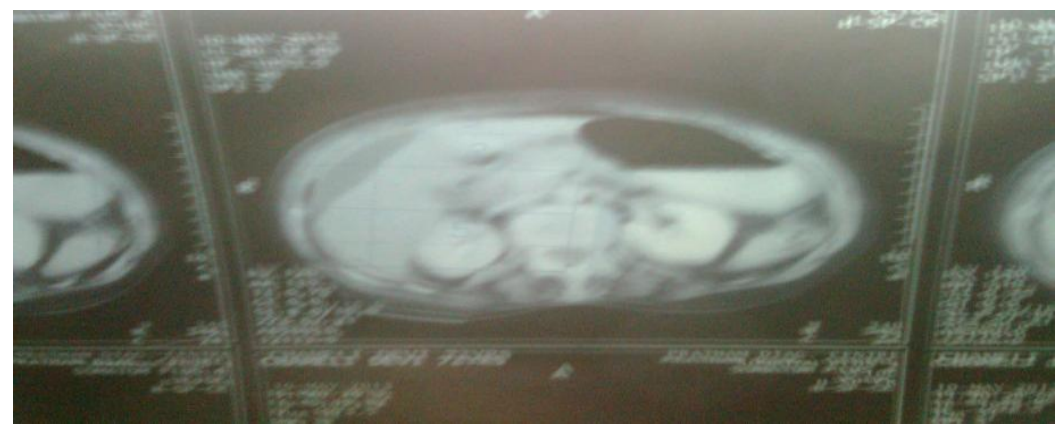

Fig. 2 C.T. scan shows perforated gall bladder and intraperitineal fluid collection. 
The patient under went an emergency laparotomy during which the finding of C.T. scan were confirmed (Fig. 3). A cholecystectomy \& generous peritoneal lavage was performed. Histopathology attested a perforated gall bladder at the body.

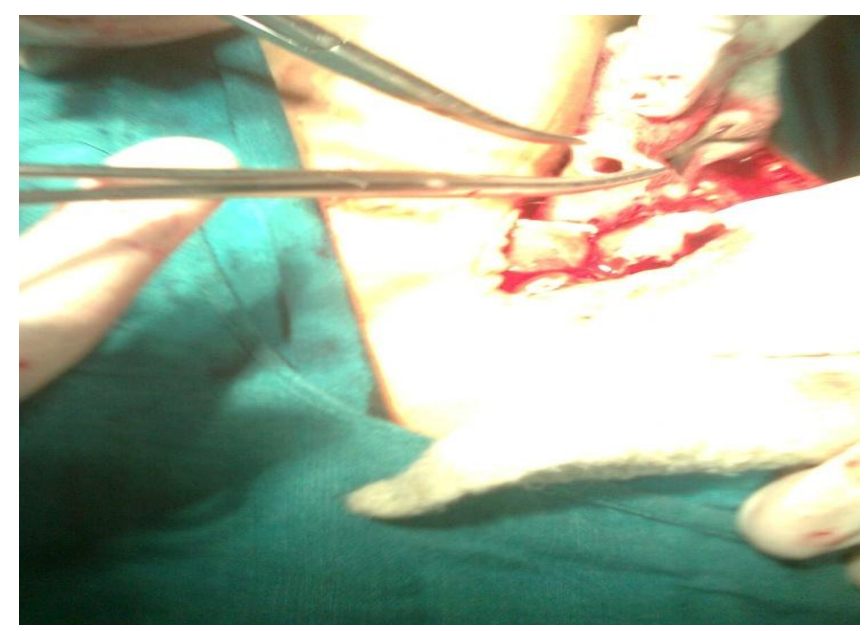

Fig. 3 Per operative photograph-arrow pointing towards gall bladder perforation.

\section{DISCUSSION}

Perforated gall bladder constitutes up to $2 \%$ cases of acute biliary emergencies ${ }^{1}$. Steroid therapy has an effect on gall bladder function. It has been suggested that steroid impair functions of smooth muscle of gall bladder that may lead to chronic distension ${ }^{2}$. Gall bladder hypomotality due to down regulating $\mathrm{G}_{\mathrm{i} 3}$ proteins caused by oral steroid has been demonstrated in animal models ${ }^{3}$ The fundus of gall bladder is the least vascularised part of the organ ${ }^{4}$ Chronic distension due to impaired emptying coupled with poor vascularity may increase chances of gall bladder perforation. Prolonged steroid therapy lowers the resistance of biliary tree to bacterial invasiveness and suppresses the process of repair of a locally damaged gall bladder ${ }^{5}$. Steroids also mask the clinical signs.After a Medline search, we found two cases (reported by H.J. Gonsalves) where perforation of an acalculous gall bladder was reported in a patient who was on prednisolone for rheumatoid arthritis.It is notable in our case that white cell count and temperature was raised and clinical signs were subtle. USG \& C.T. scan is helpful in these equivocal cases but the final diagnosis is achieved only peroperatively.Surgery is usually straight forward as there is minimal inflammatory response surrounding the gall bladder. Laparoscopy and proceed is suggested. A high index of suspicion and open mind is the key in managing such patients.

\section{CONCLUSSION}

Patients on steroid therapy are compromised and the acute inflammatory response is impaired. Decreased gall bladder motility due to long term steroid use may lead to chronic distention. The vicious combination of these phenomena makes this organ prone to perforation.

\section{REFERENCES}

[1.] Macdonald J.A. Perforation of gall bladder associated with acute cholecystitis: 8 years review of 20 cases. Ann. Surg. 1966, 164(5)849-52

[2.] Tiemey, Nakeeb A, wongo, et al. Progesterone alters biliary flow dynamics. Ann. Surg. 1999, 229(2)205-9

[3.] Chen Q chitinavis V, Xiao Z, et al. impaired G protein function in gall bladder muscle from progestrone treated guinea pigs. Am. J. physiol. 1998, 274(2pt.1):G283-9.

[4.] Williams PL, warwick R, Dyson M, Bannister LH. Vascular supply of the gall bladder. In: Gray`s text book anatomy. $37^{\text {th }}$ ed. London: churchil livingstone, 1989, p 769.

[5.] Gonsalvers H.J. Spontaneous perforation of gall bladder due to acute noncalculous ulceratibe cholecystitis. J.R. Coll. Surg. Edinb 1979, 24(3):159-61. 